\title{
Research article \\ Usefulness of serum globulin levels for discriminating patients with monoclonal gammopathies/ paraproteinemias
}

\author{
Neelam M Pawar' ${ }^{1}$ Anupama Hegde ${ }^{2}$ \\ ${ }^{1}$ Assistant Professor, ${ }^{2}$ Professor \& Head, Department of Biochemistry, Kasturba Medical College, Mangalore, (Manipal \\ Academy of Higher Education, Manipal) 575004, Karnataka India
}

(Received: October $2020 \quad$ Revised: February $2021 \quad$ Accepted: March 2021)

Corresponding author: Anupama Hegde. Email: anupama.hegde@manipal.edu

\begin{abstract}
Introduction and Aim: The confirmatory step in diagnosis of monoclonal gammopathies is bone marrow biopsy and presence of M-protein in serum protein electrophoresis. These tests are relatively expensive \& invasive for screening and unavailable in low resource settings. Increased levels of serum globulin are clue to the diagnosis of monoclonal gammopathy. The aim of this study was to assess the relevance of serum globulin levels in discriminating between patients with \& without monoclonal gammopathies/ paraproteinemia.

Materials and Methods: We retrospectively reviewed serum protein electrophoresis (SPE) and related investigations of patients suspected of monoclonal gammopathy. Reports with an M-band were considered as paraproteinemias, and those without as controls. ROC for sensitivities \& specificities for serum globulin levels were computed.

Results: For the case-control study, median serum globulin values in cases were 4.4 (3.5-6.3) g/dL in males and 3.65 $(3.33-5.0) \mathrm{g} / \mathrm{dL}$ in females. They were significantly higher than those with normal SPE pattern, with a $\mathrm{p}<0.001$. A cut-off value of $3.25 \mathrm{~g} / \mathrm{dL}$ of globulin could distinguish between paraproteinemias and controls with a sensitivity of $82.1 \%$ and specificity of $85.4 \%$ in males; a sensitivity of $79.2 \%$, a specificity of $76.7 \%$ for females. At a cut-off value of $3.4 \mathrm{~g} / \mathrm{dL}$, sensitivity was $77 \%$ and specificity $92.7 \%$ for males; sensitivity was $75 \%$ and specificity $83.7 \%$ for females. Alternatively, a cut-off value of 0.458 of globulin/total protein ratio could distinguish at a best sensitivity \& specificity of $80 \%$ and $89 \%$ in males; $83.3 \%$ and $83.7 \%$ in females.
\end{abstract}

Conclusion: Serum globulin values and globulin/total protein ratio can reliably differentiate patients with paraproteinemias.

Keywords: Monoclonal gammopathies; paraproteinemia; serum globulin; M-protein, SPE.

\section{INTRODUCTION}

$\mathrm{T}$ he 'paraprotein', synonymous with monoclonal component, M-protein or monoclonal protein, has been valued over a long period of time as crucial biomarker in monoclonal gammopathies/ paraproteinemias (1). Monoclonal gammopathies range from the benign to the malignant plasma cell dyscrasias (PCD) including monoclonal gammopathy of undetermined significance (MGUS), smouldering multiple myeloma (SMM) and multiple myeloma (MM) to name few (1).

Serum M-protein concentration $<3 \mathrm{~g} / \mathrm{dL}$ and plasma clonal cells of less than $10 \%$ in the bone marrow are characteristic of MGUS. SMM is asymptomatic, identified as $\geq 3 \mathrm{~g} / \mathrm{dL}$ of M-protein and/or $10-60 \%$ infiltration of bone marrow by plasma cells. Both of them feature no myeloma-defining end organ damage (2).

Among haematological malignancies, multiple myeloma stands the $2^{\text {nd }}$ most common in adults in the western population and accounts for nearly $1 \%$ of all cancers $(3,4)$. MGUS identified patients require monitoring, especially after the age of 50 , since 0.5 -
$1 \%$ of them progress to multiple myeloma per year (3, $5)$.

Serum protein electrophoresis (SPE) is recommended in patients presenting with indistinct clinical symptoms like anaemia, weakness and malaise, with or without bony pain, to detect and quantify monoclonal component (5-7). However, due to its asymptomatic nature, MGUS has been a challenge to diagnose, and screening for the same is not a common clinical practice(5). The higher cost of electrophoresis testing discourages clinicians from using it as a screening tool in the absence of a strong clinical suspicion for paraproteinemia/ monoclonal gammopathies.

The non-albumin fraction in serum total protein is comprised of the globulin proteins $(8,9)$. Also denoted as 'gamma gap', when elevated, is seen in monoclonal gammopathies as well in several acute infections and chronic inflammatory conditions. It remains a worthwhile screening tool in the clinical setting as it enables their early diagnosis $(8,10)$.

Multiple myeloma can present with a wide array of symptoms including hypercalcemia, non- iron deficiency anaemia, renal impairment, bony pain, etc. 
These symptoms are evaluated for myeloma if they cannot be explained otherwise (11). While an increased globulin level is consistently observed in multiple myeloma, and a study on an association of globulin levels at diagnosis with the treatment response and overall survival in patients with MM is reported (12), data available on the clinical utility of globulin values for distinguishing the risk of presence of paraproteinemias is insufficient. The aim and objectives of this present study was to assess whether serum globulin values can be used as an inexpensive tool in the discriminating between patients with and without paraproteinemia, especially when clinical features are inconclusive; to help identify such patients for reflex testing and establishing evidence with SPE and bone marrow biopsy.

\section{MATERIALS AND METHODS}

\section{Study design}

The Institutional Scientific Committee approved the study protocol. The results of serum protein electrophoresis reports of all patients, referred for investigation of suspected monoclonal gammopathy, were retrospectively reviewed between August 2017 and August 2019 in the clinical biochemistry laboratory at Kasturba Medical College Hospital, Mangalore. SPE reports of patients showing one/multiple sharp M-band/spike in any of the globulin regions were corroborated with bone marrow biopsy reports, and those reported as suggestive of paraproteinemia were defined as cases. SPE reports without any sharp M-bands showing normal patterns were included as controls. Patients undergoing treatment for monoclonal gammopathies at the time of the test, patterns with diffuse globulin increase, and repeat tests were excluded from the study.

\section{Data Collection}

The data related to the gender; age; total protein, albumin, globulin levels and bone marrow biopsy reports were recorded from electronic records of the biochemistry department. Their medical, drug and treatment history were extracted from medical records of their outpatient and inpatient files.

\section{Laboratory tests}

Serum was separated from venous blood samples of subjects. Laboratory testing was performed at the hospital central laboratory within $1 \mathrm{~h}$ after collection. Biochemical indexes, such as total protein (TP), albumin (ALB), were measured using an automated chemical analyser (COBAS 6000 c501, Roche, Germany) and associated reagents with biuret and BCG method, respectively, were used. Serum globulin (G) was calculated as Total protein-Albumin (9). Serum globulin/Total protein values were calculated as a ratio. The SPE was run using a manual agarose gel electrophoresis system (SAS-MX, Helena BioSciences, UK) according to the manufacturer's instructions. The relative percentage of each protein fraction was calculated automatically by a densitometry. $M$ protein was quantitated by the perpendicular drop method (7).

\section{Statistical Analysis}

SPSS 20.0 for Windows software (SPSS, Chicago, IL) was used to perform statistical analyses. Normality of data distribution was analysed using Shapiro-Wilk Test. Data were represented as median and percentiles wherever appropriate. Mann-Whitney U test was used for comparison of continuous data between patient groups. Receiver operating characteristic (ROC) curve analysis was done for evaluating the diagnostic performance of the test. Sensitivity and specificity were reported using optimally selected cut-off values. $\mathrm{P}$ values $<0.05$ were considered as statistically significant.

\section{RESULTS}

This study included 147 patients who had a complete disease evaluation at the time of diagnosis. SPE reports of 63 patients showed a presence of M-band of which 39 were males and 24 females. Of the 84 patients with normal SPE pattern, 41 were males and 43 females. Summary of age distribution and biochemical characteristics of patients are presented in fig. 1 and table 1 respectively.

Table 1: Salient descriptive characteristics in patients with \& without paraproteinemias.

\begin{tabular}{|c|c|c|c|c|}
\hline Variable & Gender & M-band on SPE & $\begin{array}{c}\text { Normal SPE } \\
\text { pattern }\end{array}$ & P value \\
\hline \multirow{2}{*}{ Total protein (g/dL) } & $\mathrm{M}$ & $7.7(7.3-9.2)$ & $7.0(6.4-7.4)$ & $<0.001$ \\
\cline { 2 - 5 } & $\mathrm{F}$ & $7.5(6.83-8.45)$ & $7.2(6.7-7.4)$ & 0.074 \\
\hline Albumin (g/dL) & $\mathrm{M}$ & $3.3(2.6-4.0)$ & $3.9(3.65-4.5)$ & $<0.001$ \\
\cline { 2 - 5 } & $\mathrm{F}$ & $3.55(3.03-3.88)$ & $4.1(3.7-4.4)$ & $<0.001$ \\
\hline Globulin (g/dL) & $\mathrm{M}$ & $4.4(3.5-6.3)$ & $2.9(2.6-3.1)$ & $<0.001$ \\
\cline { 2 - 5 } & $\mathrm{F}$ & $3.65(3.33-5.0)$ & $3.1(2.8-3.2)$ & $<0.001$ \\
\hline \multirow{2}{*}{$\begin{array}{c}\text { Globulin/ Total Protein } \\
\text { ratio (G/TP) }\end{array}$} & $\mathrm{M}$ & $0.59(0.47-0.71)$ & $0.42(0.39-0.44)$ & $<0.001$ \\
\cline { 2 - 5 } & $\mathrm{F}$ & $0.52(0.46-0.61)$ & $0.42(0.41-0.45)$ & $<0.001$ \\
\hline
\end{tabular}

Data presented as Median (25th-75th percentile)

$\mathrm{P}<0.05$ significant; M- Male; F- Female

Non-parametric Mann Whitney $\mathrm{U}$ test for comparison of median values 


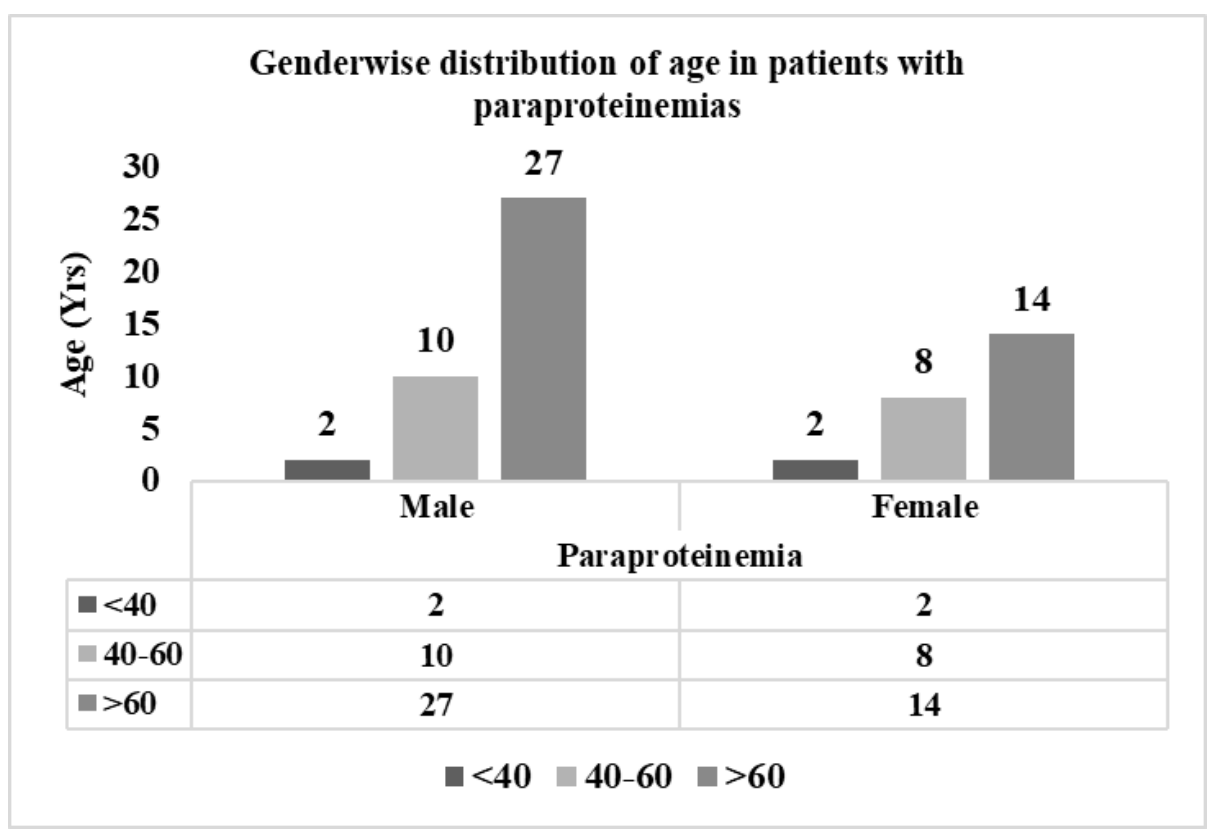

Fig. 1: Bar diagram of distribution of cases in different categories of age

Table 2: Descriptive characteristics in patients with paraproteinemias grouped by monoclonal protein concentration levels.

\begin{tabular}{|c|c|c|c|c|}
\hline Variable & Gender & M-Protein $<3 \mathrm{~g} / \mathrm{dL}(\mathrm{n}=26)$ & M-Protein $>3 \mathrm{~g} / \mathrm{dL}(\mathrm{n}=11)$ & $\mathrm{P}$ value \\
\hline \multirow{2}{*}{ Total protein $(\mathrm{g} / \mathrm{dL})$} & $\mathrm{M}$ & $7.55(1.1)$ & $10.60(4)$ & $<0.001$ \\
\cline { 2 - 5 } & $\mathrm{F}$ & $7.2(1.5)$ & $9.5(2)$ & $<0.05$ \\
\hline Albumin $(\mathrm{g} / \mathrm{dL})$ & $\mathrm{M}$ & $3.55(1.1)$ & $2.80(1.4)$ & $<0.05$ \\
\cline { 2 - 5 } & $\mathrm{F}$ & $3.55(0.9)$ & $3.45(1.1)$ & 0.27 \\
\hline \multirow{2}{*}{ Globulin $(\mathrm{g} / \mathrm{dL})$} & $\mathrm{M}$ & $3.35(1.7)$ & $7.5(5.5)$ & $<0.001$ \\
\cline { 2 - 5 } & $\mathrm{F}$ & $3.5(1.1)$ & $6.2(1.6)$ & $<0.005$ \\
\hline \multirow{2}{*}{$\begin{array}{c}\text { Globulin/ Total Protein ratio } \\
\text { (G/TP) }\end{array}$} & $\mathrm{M}$ & $0.53(0.18)$ & $0.74(0.182)$ & $<0.001$ \\
\cline { 2 - 5 } & $\mathrm{F}$ & $0.49(0.08)$ & $0.65(0.11)$ & $<0.05$ \\
\hline
\end{tabular}

Data presented as Median (Interquartile range)

$\mathrm{P}<0.05$ significant; M- Male; F- Female

Non-parametric Mann Whitney U test for comparison of median values

Median serum globulin values in patients with paraproteinemias were significantly higher $(\mathrm{p}<0.001)$ than those with normal SPE pattern, in both males and females (test statistic $\mathrm{U}=192, \mathrm{U}=213$, respectively; Fig 2).

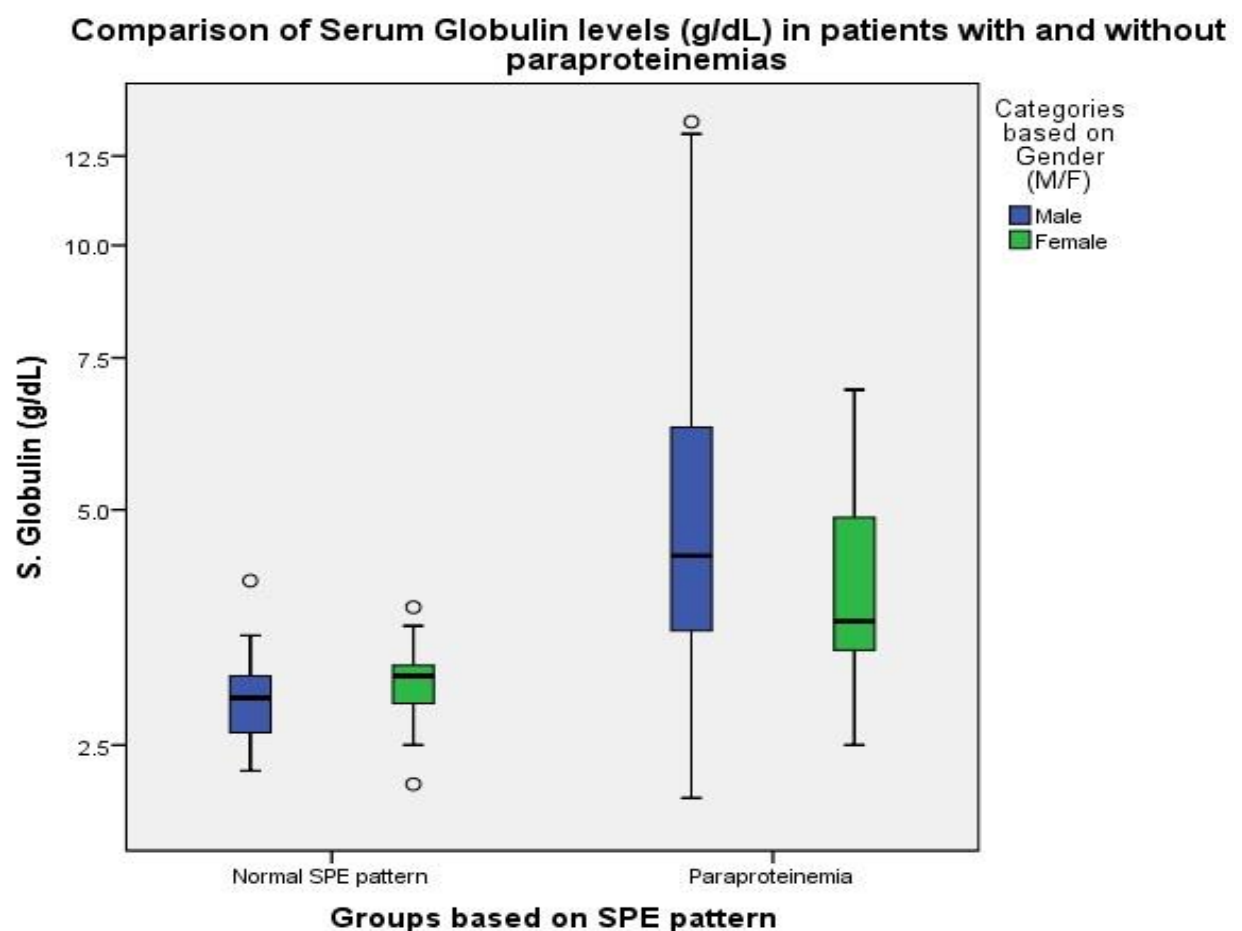

Fig. 2: Boxplot showing median serum globulin values $(\mathrm{g} / \mathrm{dL})$ in patients with and without paraproteinemias. 
At an optimal cut-off value of $3.25 \mathrm{~g} / \mathrm{dL}$, serum globulin levels could distinguish between paraproteinemias and normal patients with a sensitivity of $82.1 \%$ and specificity of $85.4 \%$ in males; a sensitivity of $79.2 \%$, a specificity of $76.7 \%$ in females (Fig. 3). At another cut-off value of $3.4 \mathrm{~g} / \mathrm{dL}$, serum globulin levels could distinguish paraproteinemias with a sensitivity was $77 \%$ and specificity $92.7 \%$ for males; sensitivity was $75 \%$ and specificity $83.7 \%$ for females. (AUC $=0.848$, CI 95\%: 0.775-0.920).

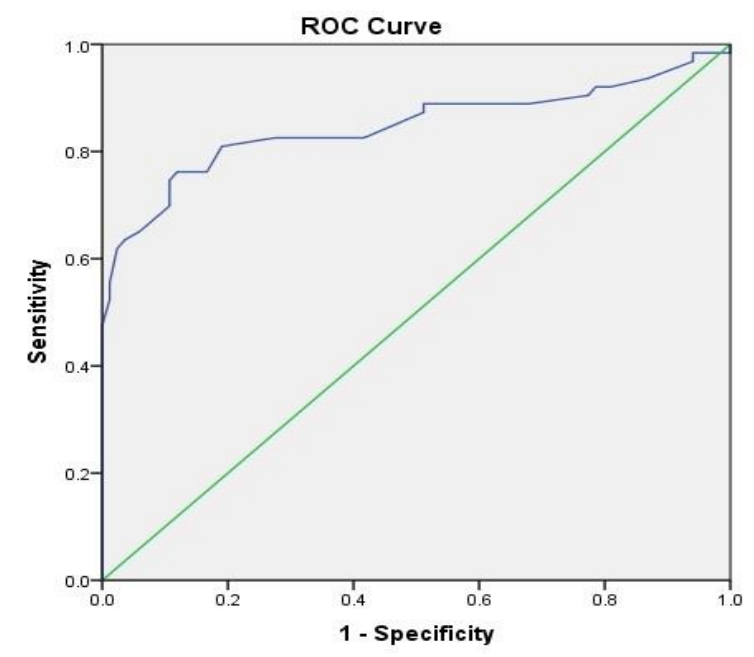

Diagonal segments are produced by ties.

Fig. 3: ROC curve analysis of serum globulin values in patients with and without paraproteinemias

Alternatively, a cut-off value of 0.458 of globulin/total protein ratio could distinguish between paraproteinemias and normal patients at a best sensitivity and specificity of $80 \%$ and $89 \%$ in males; $83.3 \%$ and $83.7 \%$ in females. $(\mathrm{AUC}=0.857$, CI 95\%: 0.790-0.924) (Fig. 4).

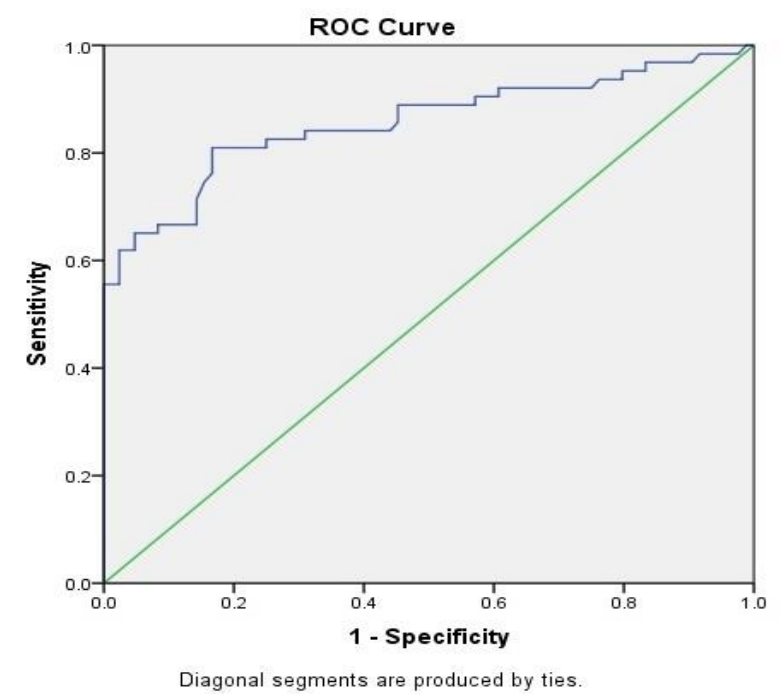

Fig. 4: ROC curve analysis of globulin/total protein ratio in patients with and without paraproteinemias

A logistic regression was performed to ascertain the effects of age, gender, serum globulin on the likelihood that participants have paraproteinemia. In the model, only globulin $(\mathrm{p}=<0.05)$ added significantly to the model prediction, but the others did not add significantly to the model. The model explained 54.3\% (Nagelkerke R2) of the variance in paraproteinemia and correctly classified $83.0 \%$ of cases. The variables in the equation output shows us that the regression equation is $1 \mathrm{n}(\mathrm{ODDS})=-9.038+$ 0.017 Age -0.466 Gender +2.313 Globulin ratio.

For the present study, assuming an alpha level of 0.05, difference between means of 2.1, sigma difference of 2, power calculated for two tailed test was 0.9997 .

\section{DISCUSSION}

The multiple myeloma incidence in India reportedly stands at 1.9 per 100,000 persons (13). However, the prevalence data of monoclonal gammopathies in India is insufficient, as well as inconsistent due to differential inclusion criteria. Several studies have reported varying data depending on the population that was evaluated on suspicion of monoclonal gammopathies. In 2010, Singh et al., (14), observed monoclonal gammopathy in $7.5 \%$ of patients of the screened population. In 2018, Gupta et al., (13) published an overall prevalence of MGUS at $1.43 \%$, lower than that reported for global population. In 2019, a study by Bora (15), reported 1916 of documented cases of MM as registered in the National Cancer Registry Programme reports, which accounted for $1.19 \%$ of all cancers. These findings indicate the need to invest in screening methods for monoclonal gammopathies in patients within appropriate age groups.

In the present study, SPE showing the presence of Mband were seen higher in men than women. This is consistent with an Indian study published by Shaft et al., where male to female ratio of 1.4:1 was observed (16). However, other Indian studies have found monoclonal gammopathies higher in women (14).

In the present study, serum globulin values as well as globulin/total protein (G/TP) ratios in patients with paraproteinemias were significantly higher than those with normal SPE pattern. In the present study, cut-off values for best sensitivities \& specificities of serum globulin levels (3.25-3.4 g/dL) demonstrated reliable discrimination between patients with and without paraproteinemias. This is similar to study by Thakkinstian et al., (17), who in 2008, tried to develop a clinical decision rule with variables like age, gender, globulin, haemoglobin, etc in patients that were associated with presence of a paraprotein. The factor found most significant by them was globulin, with levels higher than $4.1 \mathrm{~g} / \mathrm{dL}$ having five-fold higher odds of having a paraprotein proposing that higher gamma gap was a strong predictor for reflex testing with electrophoresis. Mitchell et al., reported an increased detection rate (4\% more) of monoclonal gammopathies when patients with elevated plasma globulins were investigated further. Serum gamma globulins greater than $4 \mathrm{~g} / \mathrm{dl}$ were associated with an $76 \%$ incidence of monoclonal gammopathies (18). In 
2015, Juraschek et al., also reported a gamma gap of $3.1 \mathrm{~g} / \mathrm{dl}$ or more was associated with $30 \%$ higher risk of death (19). A study summarized risk stratification markers and tools for MM as recently as in 2020 (20).

\section{CONCLUSION}

The findings in the present study indicate serum globulin values and globulin/total protein ratio can differentiate between patients with and without paraproteinemias with moderate sensitivity and specificity. To conclude, in low resource settings, and for continuous monitoring of patients in the elder age group, elevated globulin levels can be a useful diagnostic tool to help identify at-risk individuals before they become "patients with bad prognosis", to help identify/ prioritize such patients for reflex testing and establishing evidence with SPE and bone marrow biopsy, especially in asymptomatic patients. Consequently, pro-actively screen patients for monoclonal gammopathies.

\section{Limitations of the study}

Study population could have been higher; due to missing tests, other biochemical tests that are known to be deranged in monoclonal gammopathies could not be analysed \& assessed.

\section{ACKNOWLEDGEMENT}

We would like to express our gratitude to Ms. Himani Kotian, Lecturer cum Biostatistician for assistance in sample size calculation and grateful to Dean, Kasturba Medical College, Mangalore for providing the facilities for completing the study.

\section{CONFLICT OF INTEREST}

Authors declare no conflict of interest.

\section{REFERENCES}

1. Tate, J. R. The paraprotein - An enduring biomarker. Clin Biochem Rev. 2019; 40(1): 5-22.

2. Rosen, S. T., Roccaro, A. M., Ghobrial, I. M. Plasma cell dyscrasias. Cancer Treatment and Research; 2016. Available from: https://www.springer.com/gp/book/9783319403182

3. Hultcrantz, M., Morgan, G. J., Landgren, O. Multiple myeloma and other plasma cell dyscrasias [Internet]. Oncologic Therapies. 2017. 489-507 p. Available from: https://link.springer.com/content/pdf/10.1007\%2F978-3319-25586-6.pdf

4. Bornhorst, J. Protein marker evaluation of monoclonal gammopathies. Clin Lab News. 2015; 1-7.

5. Tripathy, S. The role of serum protein electrophoresis in the detection of multiple myeloma: An experience of a corporate hospital. J Clin Diagnostic Res. 2012; 6(9): 1458-1461.

6. Chan, P. C., Yasodhara, A., Truong, D. Bisalbuminemia : Lack of association with monoclonal gammopathy and valuejustification for reporting in serum protein electrophoresis. J Clin Chem Lab Med. 2017; 1(1): 1-4.

7. J, R. B., Sharma, B. K., Furruqh, S. A study to evaluate immunoglobulins fraction by serum protein electrophoresis for occurrence of multiple myeloma in a tertiary care hospital. Int J Biomed Res. 2017;8(7):397-403.

8. Loprinzi, P. D., Addoh, O. The gamma gap and all-cause mortality risk: considerations of physical activity. Int J Clin Pract. 2016;70(7): 625-629. Busher, J. T. Serum albumin and globulin. clin methods hist phys lab exam. 1990; Available from: http://www.ncbi.nlm.nih.gov/pubmed/21250048

9. Sakalova, A., Holomanova, D., Mistrik, M., Hrubiško, M., Gažová, S., Chabroňová, I., et al., Current problems of early recognition of primary malignant monoclonal gammopathy. [Slovak]. Lekarsky Obzor. 2004; 53 (5): 177-183

10. Eslick, R., Talaulikar, D. Multiple myeloma: from diagnosis to treatment. Aust Fam Physician. 2013; 42(10): 684-8. Available from: https://www.racgp.org.au/download/Documents/AFP/2013/ Oct/201310eslick.pdf

11. Eren, R., Ozdemir, O., Aslan, C., Dogu, M., Altindal, S. and Yokus, O., et al., The association of globulin levels with treatment response and survival in multiple myeloma patients. Eurasian J Med Oncol. 2017; 22 ): 61-64.

12. Gupta, R., Dahiya, M., Kumar, L., Shekhar, V., Sharma, A., Ramakrishnan, L., et al., Prevalence of monoclonal gammopathy of undetermined significance in India-A hospital-based study. Clin Lymphoma, Myeloma Leuk. 2018; 18(9): e345-350.

13. Singh, K., Singh, B., Arora, S., Saxena, A. Immunological evidence of monoclonal gammopathy in North India: a hospital based study. Pathol Lab Med Int. 2010; 107.

14. Bora, K. Distribution of multiple myeloma in India: Heterogeneity in incidence across age, sex and geography. Cancer Epidemiol. 2019;59:215-220. doi:10.1016/j.canep.2019.02.010

15. Shaft, M., Zargar, M., Shah, Z. A., Salahuddin, M., Siddiqi, M., An immunological based study of monoclonal gammopathies among suspected individuals in Kashmir region. Indian J Clin Biochem. 1998; 13(2): 106-110.

16. Thakkinstian, A., Tran, H., Reeves, G., Murch, S., Attia, J., A clinical decision rule to aid ordering of serum and urine protein electrophoresis for case-finding of paraproteins in hospitalized inpatients. J Gen Intern Med. 2008; 23(10): 1688-1692.

17. Mitchell, E. B., Ali, M.A.M., Keane, P., Bienenstock, J.,The value of elevated gamma globulins in the diagnosis of monoclonal gammopathy and multiple myeloma. Ir J Med Sci. 1983; 152(9): 349-352.

18. Yang, M., Xie, L., Liu, X., Hao, Q., Jiang, J., Dong, B., et al., The gamma gap predicts 4-year all-cause mortality among nonagenarians and centenarians. Sci Rep. 2018;8(1):4-9. https://doi.org/10.1038/s41598-018-19534-4.

19. Kapoor, R., Kumar, R., Dubey, A. P. Risk stratification in multiple myeloma in Indian settings. Indian J Hematol Blood Transfus. 2020;36(3):464-472. doi:10.1007/s12288-01901240-4. 